\title{
Anesthetic Management with Sevoflurane for Internal Fixation of Long Bone Fracture in a Horse
}

\author{
Yutaka MIZUNO ${ }^{1}$, Norio OHASHI ${ }^{1}$, and Hiroko AIDA $^{2 *}$ \\ ${ }^{1}$ Miho Training Center, Equine Veterinary Clinic, Japan Racing Association, 2500-2 Oaza-Mikoma, Miho-

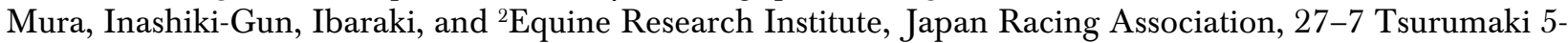 \\ chome, Setagaya-ku, Tokyo 154, Japan
}

We used sevoflurane for inhalation anesthesia for internal fixation of a fracture of the tibia in a 3-year-old Thoroughbred race horse. The stage of surgical anesthesia was maintained by an end-tidal sevoflurane concentration of 2.6-2.9\%. The anesthesia time was $7 \mathrm{hr}$, and the time from extubation until standing was $2 \mathrm{hr}$ in this case. No marked problems on pulmonary and cardiovascular function have been observed during surgery in this case. The postoperative creatinine phosphokinase and lactate dehydrogenase levels were markedly high 17,280 and 5,080 U/l, respectively), and induration swelling was observed in the musculus longissimus of the back and the mesogluteus. These findings suggest myopathy. However, no marked postanesthetic problems such as difficulty in standing developed. Sevoflurane seems to be a safe anesthetic for long term inhalation anesthesia in horses. The maintenance concentration of sevoflurane seen in this horse clinically supported the estimated concentration based on the minimum alveolar concentration of sevoflurane.

Key words: anesthesia, horses, myopathy, sevoflurane
J. Equine Sci.

Vol. 7, No. 2

pp. $47-50,1996$
Sevoflurane, a volatile anesthetic, is widely used in humans $[4,5]$ and small animals. It has the advantage of rapid induction, easy management of anesthesia, and rapid recovery. The minimum alveolar concentration (MAC) of sevoflurane was reported to be $1.70 \%$ in humans [7], 2.36\% in dogs [3], and 2.31\% in horses [1]. The degree of suppression of cardiopulmonary function by sevoflurane is similar to that by isoflurane in horses [2]. There have not been any reports on the clinical use of sevoflurane in horses. We report anesthetic management with sevoflurane for inhalation anesthesia in the repair of a fracture tibia in an adult Thoroughbred race horse.

A 3-year-old male race horse weighing $444 \mathrm{~kg}$ developed a severe fracture of the left tibia during training. Internal fixation with two plate (Dynamic Compression Plate, Synthes, Paoli, USA) and large cortex screws was performed. After sedation with $1.0 \mathrm{mg} / \mathrm{kg}$ of xylazine, $500 \mathrm{ml}$ of $10 \%$ guaiacolglycerin ether mixed with $2 \mathrm{~g}$ of thiopental sodium was rapidly injected

This article was submitted March 6, 1996, and was accepted June 29, 1996.

*corresponding author. intravenously for induction of anesthesia. After induction and endotracheal intubation, the horse was restrained on the surgical table in the dorsal recumbency.

Anesthesia was maintained by sevoflurane (Sevofrane, Maruishi Pharmaceutical Co. Ltd., Osaka) in oxygen. An anesthetic machine for large animals (MOK 94, Silver Medical, Tokyo) was used. As a vaporizer, a PPV $\Sigma$ with a maximum output of 7\% (Penlon Ltd., Oxon, UK) was used. Twenty minutes after the start of inhalation anesthesia, spontaneous ventilation was changed to controlled ventilation, and the arterial carbon dioxide tension was maintained in the range of 45-55 $\mathrm{mmHg}$. In addition, dobutamine was intermittently administered to maintain the mean arterial blood pressure at about 70 $\mathrm{mmHg}$. Lactated Ringer's solution was also infused at a rate of $10 \mathrm{ml} / \mathrm{kg} / \mathrm{hr}$

The end-tidal sevoflurane concentration $\left(\mathrm{ET}_{\mathrm{SEVO}}\right)$, heart rate, electrocardiograms, arterial blood pressure, respiratory rate, tidal volume, and arterial blood gases and $\mathrm{pH}$ were measured at $10 \mathrm{~min}$ intervals from the start of inhalation anesthesia. Blood count and serum biochemical profile were performed from standing to 12 days after surgery. The $\mathrm{ET}_{\mathrm{SEVO}}$ was measured with an 
anesthetic gas monitor (Type 1304, Bruel \& Kaer, Copenhagen, Denmark) by aspirating the expired gas from the channel at the Y-piece. For the measurement of the arterial blood pressure, a catheter was inserted into the facial transverse artery, and the zero level of the pressure transducer was fixed at the height of the right atrium. The tidal volume was measured using a flowmeter (6800 Volume Monitor, Bird, Palm Spring, USA) connected between the expiratory circuit and the soda lime canister.

The surgery time was $6 \mathrm{hr}$ and $20 \mathrm{~min}$, and the anesthesia time was $7 \mathrm{hr}$. No abnormal findings that would require emergency treatment were noted during or after anesthesia. Serial changes in the measurement items such as the $\mathrm{ET}_{\mathrm{SEVO}}$ are shown in Table 1. At the start of inhalation anesthesia, the oxygen flow volume was set at $8 \mathrm{l} / \mathrm{min}$, and the vaporizer dial at 7.0. After spontaneous ventilation for about $15 \mathrm{~min}, \mathrm{ET}_{\text {SEVO }}$ increased to $3.4 \%$ which showed disappearance of nystagmus and eyelid reflex as the II to III phase of the surgical plane. For the surgical stage of anesthesia, the oxygen flow volume was set at $5 \mathrm{l} / \mathrm{min}$. Seventy minutes or more after the initiation of anesthesia, the vaporizer dial was set at 3.5-5.0, and the mean $\mathrm{ET}_{\mathrm{SEVO}}$ corresponding to this was $2.6-2.9 \%$. The mean heart rate was $31.7-36.2 / \mathrm{min}$, and no arrhythmia occurred.

The mean arterial blood pressure decreased with the start of anesthesia, reaching the minimum value $(55$ $\mathrm{mmHg}$ ) after $30 \mathrm{~min}$, and was subsequently maintained at $68.5-82.5 \mathrm{mmHg}$. The arterial carbon dioxide tension after the start of controlled ventilation was maintained at $43.8-60.8 \mathrm{mmHg}$. The time from extubation until standing was $120 \mathrm{~min}$. After standing, discomfort in the posterior body was observed, although marked severe lameness was not seen. Twelve hours after standing, swelling and induration was observed in the musculus longissimus of the back and the mesogluteus, and there was little spontaneous movements of the horse in the box.

Serial changes in blood profiles are shown in Table 2. Creatinine phosphokinase, gultamic oxaloacetic transaminase, and lactate dehydrogenase markedly increased after surgery, reaching peak values of 17,280, 1,353 , and 5,080 U/l, respectively, after 12 or $24 \mathrm{hr}$, they returned to normal values 12 days after surgery. The erythrocyte count, total protein, albumin, $\gamma$-glutamyl transpeptidase, alkaline phosphatase, $\mathrm{Na}$, and $\mathrm{K}$ altered within normal limits during the evaluation period.

The stage of surgical anesthesia in inhalation anesthesia is considered to be maintained at an end-tidal anesthetic concentration of 1.2 MAC [10]. Therefore, the maintenance concentration of sevoflurane in horses is estimated to be about $2.8 \%$. In this case, surgery could be performed in the $\mathrm{ET}_{\text {SEVo }}$ range of 2.6-2.9\%. This maintenance concentration clinically supports the estimated concentration based on the sevoflurane MAC.

No marked problems on respiratory and cardiovascular function have been observed during surgery in this case.

General anesthesia in horses may lead to difficulty in standing due to postoperative myopathy caused by compression of the muscle tissue over a long period and suppression of the cardiovascular system such as hypotension [6]. In this case, the anesthesia time was longer than usual in horses, and the time until standing was prolonged. Creatinine phosphokinase and lactate dehydrogenase, which indicate the state of damage of muscle tissue after surgery [11], were markedly higher than the range of physiological changes after anesthesia [9]. In addition, induration swelling was observed in the musculus longissimus of the back and mesogluteus which might be attributed to the position of the horse on the operating table. These findings suggested the development of postoperative myopathy. However, this condition did not lead to severe post-anesthetic problems such as difficulty in standing or severe lameness. This may be because the horse was fixed in the dorsal recumbency, a position which infrequently causes myopathy in the shoulder muscles, and arterial blood pressure was maintained by dobutamine administration [8].

As the duration of inhalation anesthesia increases, the amount of agent stored within the body tissues also increases and the period during which the brain anesthetic concentration is within the hypothetical ataxic range also increses. If the horses attempts to rise during this period after a long anesthetic it is likely to make repeated, unsuccessful attempts to stand with a high risk of injuring itself. In this case, horse had a good recovery sleep for longer before attempting to stand and had coordinate recovery.

The authors have also had some clinical experience of sevoflurane anesthesia on carotid artery replacement and arthroscopic surgery. No marked problems have been observed during or after surgery using sevoflurane anestheisa. In conclusion, this result of anesthetic management in this case suggested that the maintenance concentration of sevoflurane in adult Thoroughbred horses on internal fixation is about $2.6-2.9 \%$, and sevoflurane might be a safe anesthetic for prolonged inhalation anesthesia in horses. To further clarify the clinical maintenance concentration of sevoflurane in horses, it will be necessary to apply in the many clinical cases. 
Table 1. Serial changes in the measurement variables

\begin{tabular}{|c|c|c|c|c|c|c|c|c|c|c|c|c|c|}
\hline Time of anesthesia ( $\mathrm{min}$ ) & 5 & 10 & 20 & 30 & 40 & 50 & 60 & $70-120$ & $130-180$ & $190-240$ & $250-300$ & $310-360$ & $370-420$ \\
\hline Vaporizer dial setting & 7 & 7 & 6 & 5 & 5 & 4 & 4.5 & $4.4 \pm 0.4^{\mathrm{a})}$ & $3.8 \pm 0.3$ & $3.5 \pm 0.0$ & $3.7 \pm 0.3$ & $4.0 \pm 0.0$ & $3.5 \pm 0.0$ \\
\hline $\begin{array}{l}\text { End tidal sevoflurane } \\
\text { concentration }(\%)\end{array}$ & 2.8 & 3.0 & 2.6 & 2.7 & 2.6 & 2.5 & 2.6 & $2.7 \pm 0.2$ & $2.6 \pm 0.1$ & $2.7 \pm 0.1$ & $2.8 \pm 0.1$ & $2.9 \pm 0.2$ & $2.6 \pm 0.0$ \\
\hline \multicolumn{14}{|l|}{ Arterial blood pressure } \\
\hline Systolic $(\mathrm{mmHg})$ & 112 & 111 & 87 & 86 & 102 & 108 & 93 & $94.3 \pm 4.9$ & $101.5 \pm 1.6$ & $98.5 \pm 3.3$ & $95.8 \pm 3.3$ & $98.7 \pm 7.0$ & $111.7 \pm 14.5$ \\
\hline Diastolic (mmHg) & 70 & 58 & 40 & 40 & 51 & 58 & 52 & $54.3 \pm 5.6$ & $59.0 \pm 0.9$ & $57.7 \pm 3.2$ & $55.2 \pm 4.4$ & $54.8 \pm 2.8$ & $66.0 \pm 21.6$ \\
\hline $\operatorname{Meam}(\mathrm{mmHg})$ & 85 & 83 & 56 & 55 & 68 & 75 & 70 & $68.5 \pm 4.5$ & $73.2 \pm 2.9$ & $73.3 \pm 4.8$ & $70.0 \pm 5.2$ & $71.5 \pm 2.3$ & $82.5 \pm 20.8$ \\
\hline Heart rate (beat $/ \mathrm{min})$ & 30 & 30 & 32 & 29 & 28 & 29 & 28 & $36.2 \pm 1.0$ & $31.7 \pm 0.8$ & $32.7 \pm 2.0$ & $34.5 \pm 2.1$ & $32.5 \pm 1.4$ & $32.5 \pm 6.3$ \\
\hline $\begin{array}{l}\text { Respiratory rate } \\
\text { (breath } / \mathrm{min})\end{array}$ & 3 & 1 & 8 & 8 & 8 & 8 & 8 & $8 \pm 0$ & $8 \pm 0$ & $8.3 \pm 0.8$ & $8 \pm 0.6$ & $8 \pm 0$ & $8 \pm 0$ \\
\hline Tidal volume $(\mathrm{ml} / \mathrm{kg})$ & $\mathrm{ND}^{\mathrm{b})}$ & 13.1 & 10.0 & 12.2 & 14.6 & 13.1 & 12.9 & $11.9 \pm 0.7$ & $15.0 \pm 0.9$ & $14.9 \pm 0.9$ & $13.1 \pm 0.8$ & $13.3 \pm 0.0$ & $13.3 \pm 0.4$ \\
\hline Minute volume (l) & ND & ND & 35.1 & 42.2 & 52.8 & 44.8 & 45.4 & $43.1 \pm 3.6$ & $53.0 \pm 2.6$ & $60.0 \pm 3.0$ & $47.0 \pm 8.6$ & $47.0 \pm 0.2$ & $46.8 \pm 0.2$ \\
\hline $\mathrm{PaCO}_{2}(\mathrm{mmHg})$ & ND & 61.8 & 59.8 & 60.8 & 46.1 & 46.7 & 48.7 & $50.6 \pm 6.3$ & $51.5 \pm 5.2$ & $43.8 \pm 1.9$ & $46.1 \pm 3.3$ & $53.4 \pm 1.5$ & $52.5 \pm 1.7$ \\
\hline $\mathrm{PaO}_{2}(\mathrm{mmHg})$ & ND & 163 & 262 & 283 & 356 & 349 & 337 & $192.3 \pm 80.8$ & $87.8 \pm 10.1$ & $94.9 \pm 49.6$ & $96.4 \pm 40.1$ & $145.9 \pm 63.2$ & $261.3 \pm 18.5$ \\
\hline Arterial blood $\mathrm{pH}$ & ND & 7.24 & 7.27 & 7.30 & 7.34 & 7.33 & 7.37 & $7.35 \pm 0.01$ & $7.39 \pm 0.04$ & $7.44 \pm 0.01$ & $7.43 \pm 0.02$ & $7.38 \pm 0.01$ & $7.37 \pm 0.01$ \\
\hline
\end{tabular}

a): Results at 70 minutes or more expressed as the mean value of the 6 measurement values per hour and standard deviation. ${ }^{\text {b) }}$. Not done.

Table 2. Blood count and serum biochemical profile on pre and after anesthesia

\begin{tabular}{|c|c|c|c|c|c|c|c|c|c|c|}
\hline \multirow{2}{*}{ Variables } & \multirow{2}{*}{ Pre $^{\text {a) }}$} & \multirow{2}{*}{$\begin{array}{l}1 \mathrm{hr} \text { after } \\
\text { anesthesia }\end{array}$} & \multirow{2}{*}{$\begin{array}{l}\text { Period of } \\
\text { stand }\end{array}$} & \multicolumn{7}{|c|}{ After anesthesia (hr) } \\
\hline & & & & 12 & 24 & 36 & 48 & 72 & 144 & 288 \\
\hline $\mathrm{RBC}\left(\times 10^{3} / \mathrm{mm}^{3}\right)$ & 736 & $\mathrm{ND}^{\mathrm{b})}$ & ND & 788 & 830 & 797 & 773 & 690 & 833 & 908 \\
\hline $\mathrm{WBC}\left(\mathrm{mm}^{3}\right)$ & 8,100 & ND & ND & 14,200 & 9,000 & 4,900 & 5,000 & 5,000 & 7,100 & 10,000 \\
\hline $\operatorname{PCV}(\%)$ & 41.2 & 31.2 & ND & 36.8 & 34.5 & 32.9 & 31.9 & 28.0 & 34.6 & 39.2 \\
\hline $\mathrm{TP}(\mathrm{g} / \mathrm{dl})$ & 6.63 & 5.05 & 5.68 & 6.02 & 6.15 & 5.57 & 5.19 & 5.86 & 5.90 & 6.83 \\
\hline $\operatorname{ALB}(\mathrm{g} / \mathrm{dl})$ & 3.52 & 2.92 & 2.97 & 3.11 & 3.18 & 2.72 & 2.72 & 2.90 & 3.00 & 2.76 \\
\hline CPK (U/l) & 174 & 127 & 6,840 & 17,180 & 4,720 & 3,540 & 3,079 & 1,934 & 376 & 107 \\
\hline GOT (U/l) & 268 & 181 & 330 & 1,127 & 1,353 & 1,256 & 1,181 & 1,164 & 928 & 245 \\
\hline $\mathrm{LDH}(\mathrm{U} / \mathrm{l})$ & 663 & 424 & 1,524 & 5,080 & 4,902 & 3,184 & 2,709 & 2,811 & 1,770 & 433 \\
\hline$\gamma-\mathrm{GT}(\mathrm{U} / \mathrm{l})$ & 8 & 11 & 12 & 13 & 13 & 12 & 11 & 14 & 12 & 14 \\
\hline $\operatorname{ALP}(\mathrm{U} / \mathrm{l})$ & 151 & 145 & 166 & 157 & 162 & 145 & 131 & 140 & 134 & 130 \\
\hline BUN (mg/dl) & 14.7 & 16.7 & 16.5 & 21.2 & 21.2 & 19.8 & 19.6 & 20.1 & 19.1 & 16.1 \\
\hline CRE (mg/dl) & 1.3 & 1.6 & 1.8 & 2.1 & 1.9 & 2.1 & 2.5 & 3.1 & 2.1 & 1.8 \\
\hline $\mathrm{Na}(\mathrm{mmol} / \mathrm{l})$ & 131 & 137 & 136 & 138 & 141 & 134 & ND & 140 & 140 & 136 \\
\hline $\mathrm{K}(\mathrm{mmol} / \mathrm{l})$ & 4.31 & 3.58 & 3.63 & 3.15 & 3.91 & 3.45 & ND & 3.90 & 3.47 & 3.24 \\
\hline $\mathrm{Cl}(\mathrm{mmol} / \mathrm{l})$ & 97.9 & 96.9 & 97.0 & 103.3 & 107.1 & 102.4 & ND & 105.0 & 102.9 & 101.7 \\
\hline
\end{tabular}

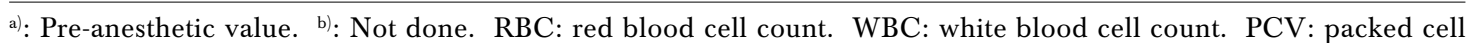
volume. TP: total serum protein. ALB: albumin. CPK: creatinine phosphokinase. GOT: glutamic oxaloacetic transaminase. LDH: lactate dehydrogenase. $\gamma$-GT: $\gamma$-glutamyl transpeptidase. ALP: alkaline phosphatase. BUN: blood urea nitrogen. CRE: creatinine.

\section{Acknowledgments}

The authors would like to thank Dr. L. Brown of the Animal Health of Abbott Laboratories in England and Mr. Takahashi of the Research and Development Department of Maruishi Phamaceutical in Osaka for advice to this study.

\section{References}

1. Aida, H., Mizuno, Y., Hobo, S., Yoshida, K., and Fujinaga, T. 1994. Determination of the minimum alveolar concentration (MAC) and physical response to sevoflurane in horses. J. Vet. Med. Sci. 56: 1161-1165. 
2. Aida, H., Mizuno, Y., Hobo, S., Yoshida, K., and Fujinaga, T. 1996. Cardiovascular and pulmonary effects of sevoflurane anesthesia in horses. Vet. Surg. 25: $164-170$.

3. Akazawa, S., Shimizu, R., and Kasuda, H. 1988. Effects of sevoflurane on cardiovascular dynamics, coronary circulation and myocardial metabolism in dogs. J. Anesth. 2: 227-241.

4. Doi, M., and Ikeda, K. 1987. Respiratory effects of sevoflurane. Anesth. Analg. 66: 241-244.

5. Furuya, Y., Tachibana, C., Kobayashi, N., Sato, K., and Ohe, Y. 1993. Comparison of sevoflurane and halothane in pediatric anesthesia. J. Anesth. 42: 4651.

6. Grandy, J.L., Steffey, E.P., Hodgson, D.S., and Woliner, M.J. 1987. Arterial hypotension and the development of postanesthetic myopathy in halothane-anesthetized horses. Am.J. Vet. Res. 48:
192-197.

7. Katoh, T., and Ikeda, K. 1987. The minimum alveolar concentration (MAC) of sevoflurane in humans. Anesthesiology 66: 301-303.

8. Mizuno, Y., Aida, H., and Fijinaga, T. 1994. Effects of dobutamine infusion in dorsally recumbent isoflurane-anesthetized horses. J. Equine Sci. 5: 8794.

9. Steffey, E.P., Farver, T., and Zinkl, J. 1980. Alterations in horse blood cell count and biochemical values after halothane anesthesia. $\mathrm{Am}$. J. Vet. Res. 41: 934-939.

10. Steffey, E.P. 1991. Inhalation anesthesia and gases. pp. 352-379. In: Equine anesthesia monitoring and emergency therapy (Muir, W.W., and Hubbell, J.A. eds.) Mosby Year Bood, St. Louis.

11. Trim, C. 1973. Post-anesthetic forelimb lameness in horses. Equine Vet.J. 5: 71-76. 